\title{
Preparation of 2,5-anhydro di-(hydrido) di-phosphate di-hydrate Mannitol (Glucitol) from Banana Fruit Yields a Possible Fructose 1,6 Bisphosphate Aldolase Inhibitor(s)
}

\author{
Jesus' Christus, Michael Arden Madson \\ Research \& Development, Bio Logistics Limited Liability Corporation, Ames, Iowa, USA \\ Email address: \\ mmadson53@earthlink.net (M. A. Madson) \\ To cite this article: \\ Jesus' Christus, Michael Arden Madson. Preparation of 2,5-anhydro di-(hydrido) di-phosphate di-hydrate Mannitol (Glucitol) from Banana \\ Fruit Yields a Possible Fructose 1,6 Bisphosphate Aldolase Inhibitor(s). World Journal of Food Science and Technology. \\ Vol. 5, No. 1, 2021, pp. 1-5. doi: 10.11648/j.wjfst.20210501.11
}

Received: January 26, 2019; Accepted: March 11, 2019; Published: January 12, 2021

\begin{abstract}
With previously unknown chemistry, 2,5-anhydro di-(hydrido)-di-phosphate-di-hydrate mannitol (glucitol) has (have) been prepared by $\mathrm{H}^{-}$nucleophilic attack of neokestose-1,6-di-phosphate from commercial banana fruit. Negative ion mass spectrometry, Inductively Coupled Mass Spectrometry (ICP-MS), both $\mathrm{ms}$ and $\mathrm{ms}^{2}$, has been used to characterize the product of this reaction. $\mathrm{NaBH}_{4}$ in $\mathrm{NH}_{4} \mathrm{OH}(\mathrm{pH}$ 11.4, IN) for 18 hours was used to convert the 1,6-di-phospho neokestose to the 2,5 anhydro derivative(s). This molecule(s) are structural analogues of the known inhibitors of fructose-1,6 bisphosphate aldolase. The known inhibitors are 2,5 anhydro mannitol and 2,5 anhydro glucitol. They have $\mathrm{K}_{\mathrm{i}} \mathrm{s}$ in the range of $10^{-3} \mathrm{mM}$. It is expected that the di-(hydrido) di-phosphate di-hydrate 2,5 anhydro mannitol (glucitol), prepared here, may be tighter binding to fructose bisphosphate aldolase than the known non-phosphorylated inhibitors, because of their structural similarity to the substrate of the enzyme, fructose-1,6-bisphosphate. If the prepared molecule(s) bind to fbp aldolase, their preparation from inexpensive banana fruit would lead to an inexpensive method for treating fast growing cancer cells. The low cost of making the molecule(s) would allow access to cancer treatment by destitute or low income people.
\end{abstract}

Keywords: Banana Fruit, Fructose-1,6-bisphosphate Aldolase (Fbp Aldolase) Inhibitors, Synthesis, Mass Spectrometry

\section{Introduction}

Fast growing cancer cells are known to require more energy. Therefore targeting glycolysis, i.e. fructose-1,6bisphosphate aldolase (fbp aldolase), with fbp aldolase inhibitors, could be effective in the treatment of fast-growing cancer cells, the Warburg effect.[1]

Both 2,5 anhydro mannitol and 2,5 anhydro glucitol are known inhibitors of fructose 1,6-bisphosphate aldolase (fbp aldolase). Their $\mathrm{K}_{\mathrm{i}} \mathrm{s}$ are in the $1.2 \times 10^{-3}$ to $3.0 \times 10^{-3}$ range, respectively. [2-4] Because of the possible increase in binding strength of the di-(hydrido) di-phosphate dihydrate analogue (s) to fbp aldolase, and that this (these) 2,5 anhydro mannitol (glucitol) analogue (s) can be synthesized, simply, from banana fruit, this (these) molecule(s) is an important target for fast growing cancer cells' treatment.

Described herein is a method for the synthesis of the title compound(s) from banana fruit. The first step is the extraction of banana fruit with ethanol (95\%). [5] Next a portion of this extract is added to $\mathrm{NH}_{4} \mathrm{OH}(\mathrm{pH} 11.4,1 \mathrm{~N})$. To this solution is added $\mathrm{NaBH}_{4}$ and the mixture allowed to stand for 18 hours at ambient temperature. The $\mathrm{NH}_{4} \mathrm{OH}$ is removed as $\mathrm{NH}_{3}(\mathrm{~g})$, by evaporation and the solution is analyzed by negative ion mass spectrometry (ICP), $\mathrm{ms}$, and $\mathrm{ms}^{2}$.

Because of the known inhibition of fbp aldolase by 2,5 anhydro mannitol and 2,5 anhydro glucitol, preparation of the di-(hydrido)-di-phosphate-di-hydrate analogues of 2,5 anhydro mannitol and 2,5 anhydro glucitol from an inexpensive source, banana fruit, and via a simple method, one step, with readily available reagents, people with fast growing cancers who are financially unable to cover the cost of expensive cancer treatments, could be treated with these analogues of fructose-1,6-bisphosphate, for cancer. 


\section{Materials and Methods}

\subsection{Isolation of Neokestose-1,6-di-phosphate}

Ripe banana, commercially available, fruit is placed in a centrifuge tube. Ten volumes of ethanol $(95 \%)$ is added and the tube shaken. The ethanol phase is collected by decantation. The ethanolic solution is analyzed by $\mathrm{ms}$ and $\mathrm{ms}^{2}$. Negative ion $\mathrm{ms}$ and $\mathrm{ms}^{2}$ were used to characterize the extract as neokestose-1,6-di-phosphate. [5-7]

\subsection{Reaction of Neokestose-1,6-di-phosphate with $\mathrm{NaBH}_{4}$ in $\mathrm{NH}_{4} \mathrm{OH}(\mathrm{pH} \mathrm{11.4,} \mathrm{1N)}$}

To a portion of ethanolic solution, noted above, $(10 \mu \mathrm{L})$ was added $\mathrm{NaBH}_{4}\left(3 \mu \mathrm{L}, 4 \mathrm{~N}\right.$ solution) and $\mathrm{NH}_{4} \mathrm{OH}(\mathrm{pH} 11.4$,

7-21-14 Sample 6B Banana MS Run 181 (0.711) Cm (4:112)

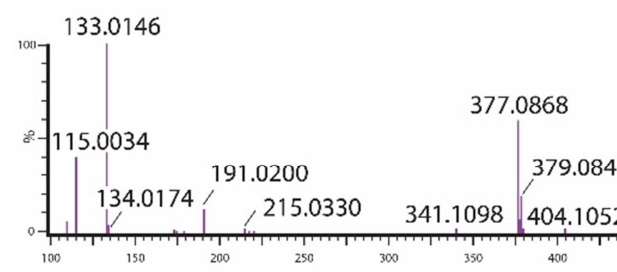

Figure 1. Mass spectrum of the reaction product of neokestose 1,6 di-phosphate after treatment with $\mathrm{NaBH}_{4}$ in $\mathrm{NH}_{4} \mathrm{OH}(1 \mathrm{~N}$, pH 11.4$)$.

Sample 6B msms $13318(0.473) \mathrm{Cm}(7: 166)$

115.0033

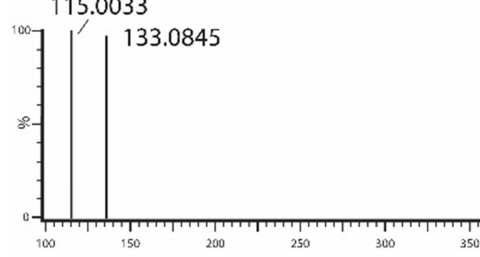

Sample 6B MSMS $21528(0.164) \mathrm{Cm}(6: 138)$

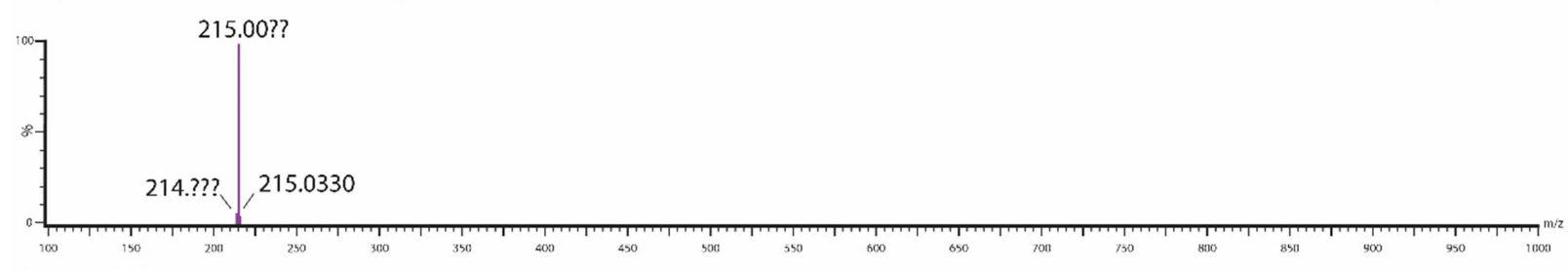

Sample 6B MSMS
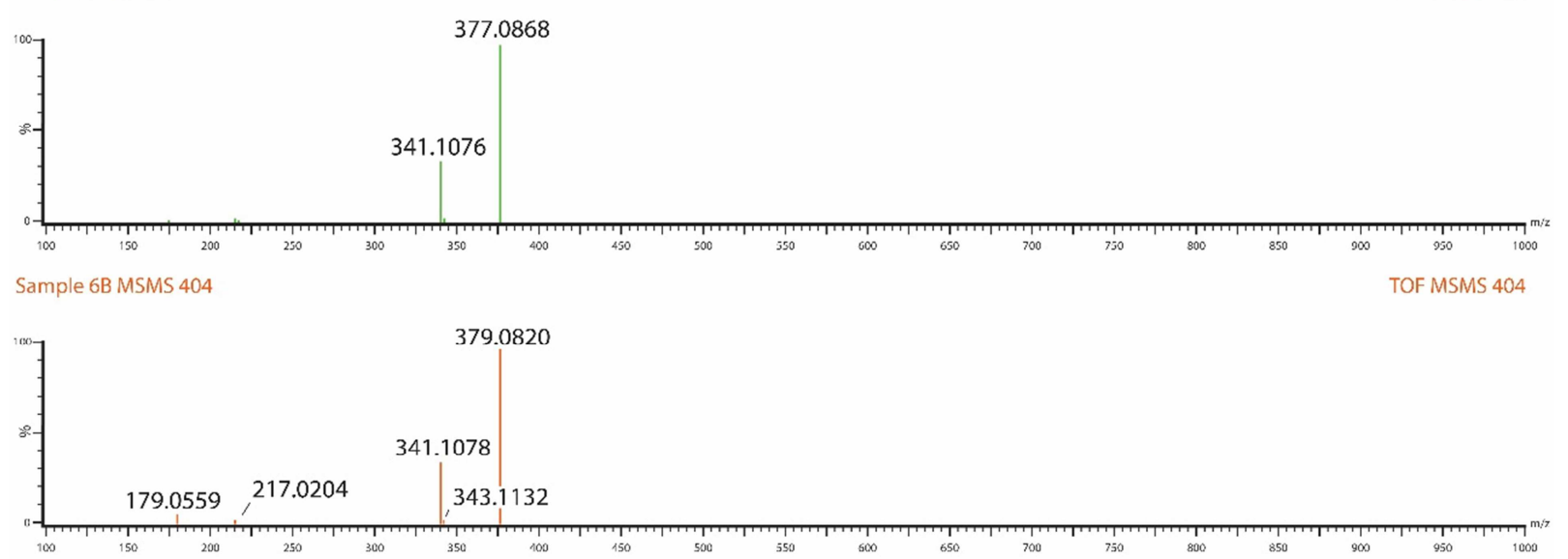

Figure 2. Tandem mass spectra of four ions noted in Figure 1 of neokestose 1,6 di-phosphate after reaction with $\mathrm{NaBH}_{4}$ in $\mathrm{NH}_{4} \mathrm{OH}$ (1 $\mathrm{N}_{\text {, }} \mathrm{pH} 11.4$ ).
$1 \mathrm{~N}, 1.00 \mathrm{~mL}$ ). The reaction mixture was allowed to stand at ambient temperature for 18 hours. The reaction mixture was evaporated with a stream of $\mathrm{N}_{2}$ to no less than $200 \mu \mathrm{L}$ to remove excess $\mathrm{NH}_{4} \mathrm{OH}$ as $\mathrm{NH}_{3}(\mathrm{~g})$. The reaction mixture was cooled to below $0^{\circ} \mathrm{C}$ while awaiting analysis by negative ion $\mathrm{ms}$ and $\mathrm{ms}^{2}$. For interpretation of $\mathrm{ms}$ and $\mathrm{ms}^{2}$ negative ion Inductively Coupled Plasma $\mathrm{ms}$ and $\mathrm{ms}^{2}$ spectra, principles described in [6] were used.

\section{Results and Discussion}

Shorter reaction times, e.g. 2 hours and 8 hours, produce only the di-(hydrido) Di-phosphate di-hydrate derivatives of neokestose 1,6-di-phosphate, as shown by negative ion ICP MS, Figure 1, ms, and Figure 2, $\mathrm{ms}^{2}$.

TOF MSES$3.90 \mathrm{e} 5$ 
This chemistry has been documented, for the case of bovine milk and $\mathrm{K}$ casein [6-7], respectively. The reason may be that the non-bonding orbital on the anomeric oxygen atom strengthens the $\mathrm{P}=\mathrm{O}$ double bond with concomitant weakening of the C-1 to O-1 bond. [8-9] Attack of hydride at the anomeric center is facilitated by the leaving group nucleo-fugicity of the O-1-phosphoryl group. This chemistry produces the 1,5-anhydro derivatives of oligosaccharides, noted in previous work. [10-11]

There is evidence for $\mathrm{H}^{-}$nucleophilic attack of the quaternary carbon, C-2 of fructofuraniosyl glucofupyranosyl fructofuranoside-1,6,-di-phosphaste, to form the corresponding 2,5-anhydro 1,6- di-(hydrido) di-phosphate di-hydrate mannitol, and the 2,5 anhydro 1,6-di-(hydrido) di-phosphate di-hydrate glucitol. This evidence is mass spectral and tandem mass spectral. Figures 3 through 7 denote fragment ions' structures. They are shown as the mannitol isomer. However, the glucitol isomer is just as likely to be formed.

In Figure 3, there is an ion, $\mathrm{m} / \mathrm{z} 404.13$; it is the di-hydrate. It loses two $\mathrm{H}^{+}$ions.

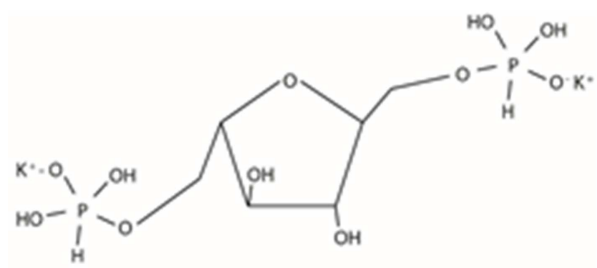

$$
\begin{gathered}
\mathrm{C}_{6} \mathrm{H}_{16} \mathrm{O}_{11} \mathrm{P}_{2}\left(\mathrm{~K}^{*}\right)_{2} \\
404.136 \text { calculated } \\
404.11 \text { found } \\
\Delta=0.026 \text { amu }
\end{gathered}
$$

Figure 3. Ion $\mathrm{m} / \mathrm{z} 40411$ from total $\mathrm{ms}$ of neokestose 1, 6 di-phosphate reaction product.

It is neutralized by $\mathrm{K}^{+}$.

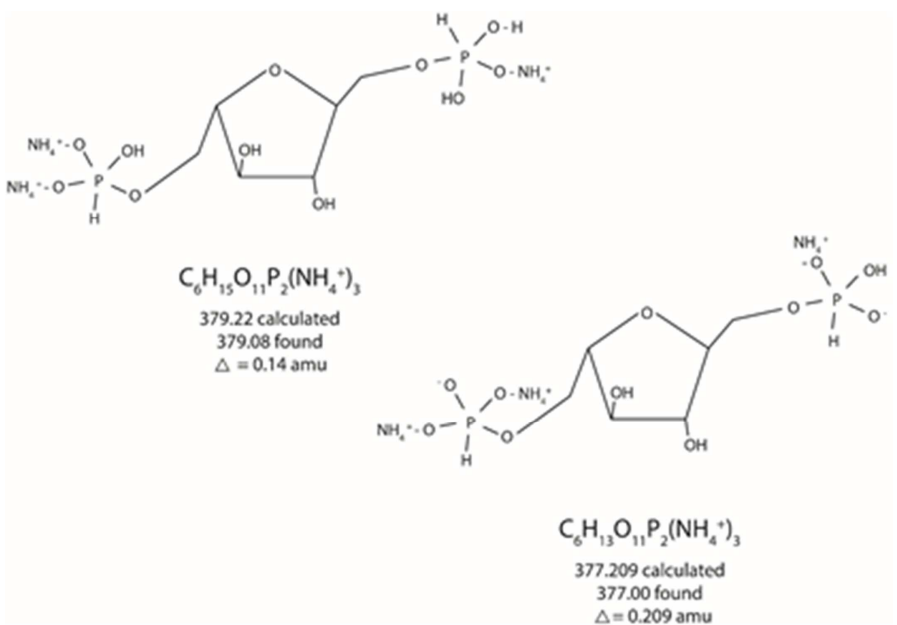

Figure 4. Ion $\mathrm{m} / \mathrm{z} 379.08$ from total $\mathrm{ms}$ and $\mathrm{ms}^{2}$ of neokestose 1, 6 di-phosphate reaction product.

In Figure 4 the ion $\mathrm{m} / \mathrm{z} 379.08$ loses two $\mathrm{H}^{+}$ions and is neutralized by $\mathrm{NH}_{4}^{+}$ions with the loss of one additional $\mathrm{H}^{+}$ ion additional $\mathrm{H}^{+}$ion.

The ion, $\mathrm{m} / \mathrm{z} 377.08$, base peak, loses two more $\mathrm{H}^{+}$ions from the 379.04 ion.<smiles>O[PH3](O)(O)O[Na]</smiles><smiles>CO[PH](O)(O)O</smiles>

$\begin{array}{cc}\mathrm{H}_{2} \mathrm{PO}_{4}\left(\mathrm{NH}_{4}{ }^{+}\right) & \mathrm{H}_{2} \mathrm{PO}_{4}\left(\mathrm{NH}_{4}{ }^{+}\right)_{2} \\ 115.032 \text { calculated } & 133.0 \text { calculated } \\ 115.003 \text { found } & 133.003 \text { found } \\ \Delta=0.029 \text { amu } & \Delta=0.003 \text { amu }\end{array}$

Figure 5. The two ions $\mathrm{m} / \mathrm{z} 133$ and $\mathrm{m} / \mathrm{z} 115.003$ are from the total $\mathrm{ms}$ and $m s^{2}$ of neokestose 1,6-di-phosphate reaction product.

The ion, $\mathrm{m} / \mathrm{z} 133.19$, is also derived from the $\mathrm{m} / \mathrm{z} 379.08$ ion. This ion loses two $\mathrm{H}^{+}$ions and it is partially neutralized by one $\mathrm{Na}^{+}$ion. The formula for this structure produces an ionic mass and it has three charges and is, therefore, divided by three. The fourth ion, $\mathrm{m} / \mathrm{z} 115.03$, is a fragmented (hydrido) phosphate hydrate less two $\mathrm{H}^{+}$ions.

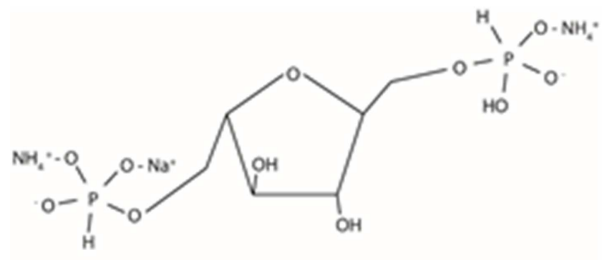

$$
\begin{gathered}
\mathrm{C}_{6} \mathrm{H}_{13} \mathrm{O}_{11} \mathrm{P}_{2}\left(\mathrm{NH}_{4}{ }^{*}\right)_{2}\left(\mathrm{Na}^{+}\right) / 2 \\
191.08 \text { calculated } \\
191.02 \text { found }
\end{gathered}
$$

Figure 6. Ion $\mathrm{m} / \mathrm{z} 191.02$ is from the total ms of neokestose 1,6 di-phosphate reaction product. 


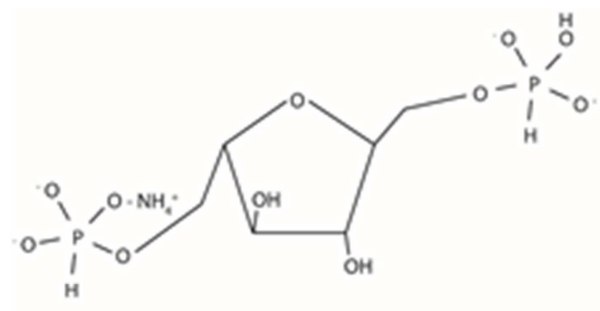

$$
\begin{gathered}
\mathrm{C}_{6} \mathrm{H}_{13} \mathrm{O}_{11} \mathrm{P}_{2}\left(\mathrm{NH}_{4}{ }^{*}\right) \\
341.13 \text { calculated } \\
341.11 \text { found } \\
\Delta=0.02 \text { amu }
\end{gathered}
$$

Figure 7. Ion $\mathrm{m} / \mathrm{z} 341.11$ from the $\mathrm{ms}$ and $\mathrm{ms}^{2}$ of the reaction of neokestose 1 , 6 di-phosphate with $\mathrm{NaBH}_{4}$ in $\mathrm{NH}_{4} \mathrm{OH}(1 \mathrm{~N}, \mathrm{pH}$ 1.4).

Ion, $\mathrm{m} / \mathrm{z} 341$, Figure 7 , could possibly come from a cleaved glucopyranosyl fructofuranoside of the neokestose1,6-di-(hydrido) di-phosphate-di-hydrate but not from the parent ion.

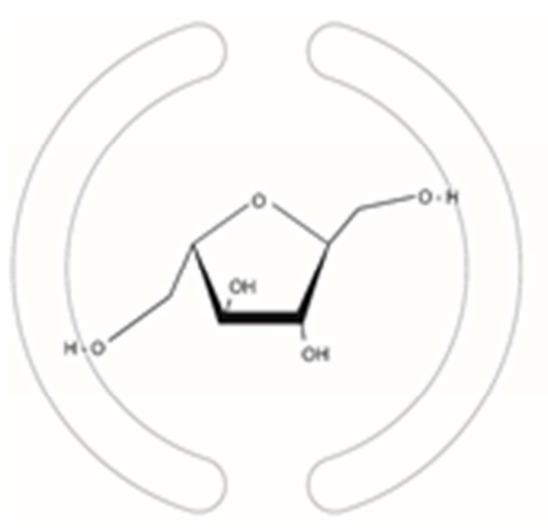

Figure 9. The two 2,5 anhydro alditols with the mannitol configuration.

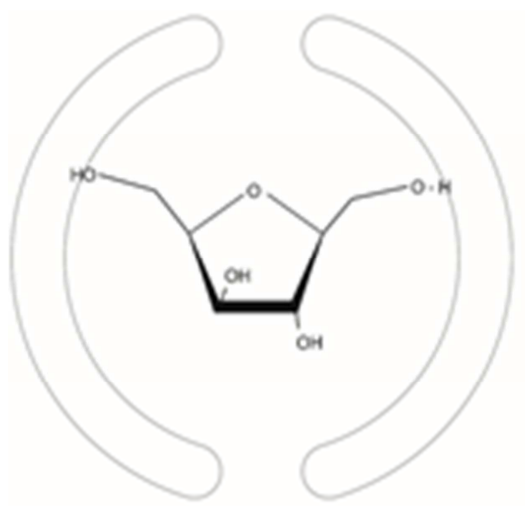

Figure 10. The 2,5 anhydro alditols with the glucitol configuration.

In Figures 9 and 10 structures are drawn as a representation for the placement of 2,5-anhydro mannitol and its di-(hydrido) di-phosphate di-hydrate at 1 and 6 positions, Figure 9, and 2,5 anhydro glucitol and its 1,6 di-(hydrido) diphosphate di-hydrate, Figure 10, in fbp aldolase. Note that, as stated previously, the placement of the primary hydroxyl groups of each molecule. The molecule with the primary hydroxyl groups farthest apart has a $\mathrm{K}_{\mathrm{i}}$ higher for the
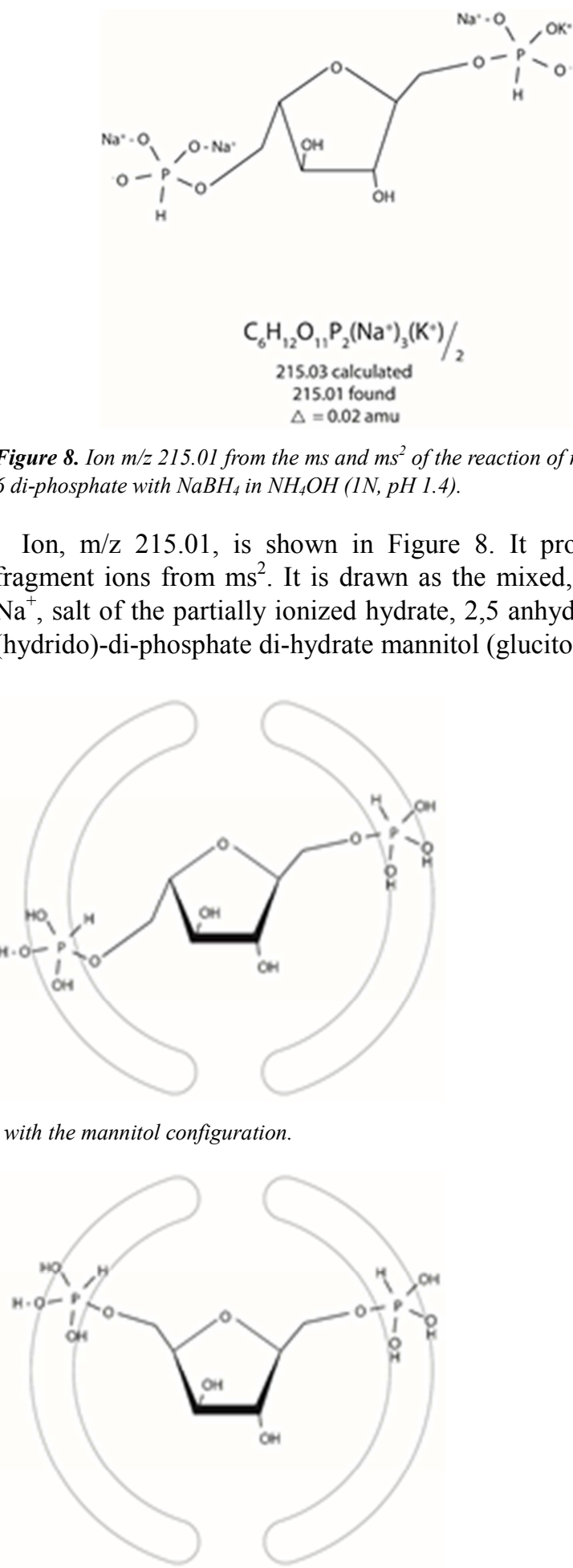

$$
\begin{gathered}
\mathrm{C}_{6} \mathrm{H}_{12} \mathrm{O}_{11} \mathrm{P}_{2}\left(\mathrm{Na}^{*}\right)_{3}\left(\mathrm{~K}^{*}\right) / 2 \\
215.03 \text { calculated } \\
215.01 \text { found }
\end{gathered}
$$

Figure 8. Ion $\mathrm{m} / \mathrm{z} 215.01$ from the $\mathrm{ms}$ and $\mathrm{ms}^{2}$ of the reaction of neokestose 1 , 6 di-phosphate with $\mathrm{NaBH}_{4}$ in $\mathrm{NH}_{4} \mathrm{OH}(1 \mathrm{~N}, \mathrm{pH}$ 1.4).

Ion, $\mathrm{m} / \mathrm{z} 215.01$, is shown in Figure 8. It produces no fragment ions from $\mathrm{ms}^{2}$. It is drawn as the mixed, $\mathrm{NH}_{4}{ }^{+}$and $\mathrm{Na}^{+}$, salt of the partially ionized hydrate, 2,5 anhydro 1,6-di(hydrido)-di-phosphate di-hydrate mannitol (glucitol).

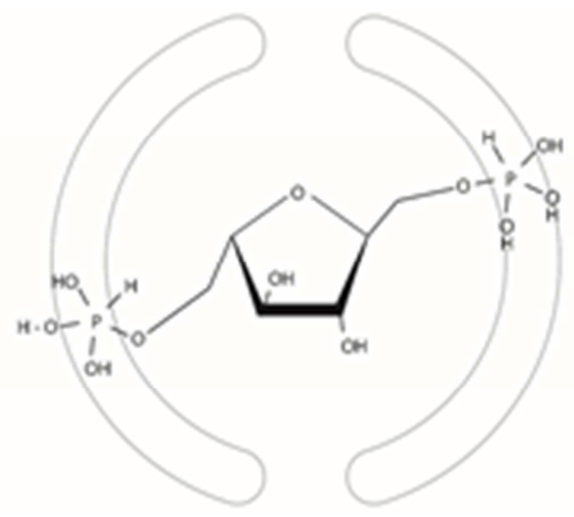

unsubstituted 2,5 anhydro alditols than the molecule with the primary groups closer to each other. Note the Figures 9 and 10 have the di-(hydrido) diphosphate di-hydrate on the right of each Figure and represents the di-(hydrido) di-phosphate di-hydrate; both 2,5 anhydro mannitol and 2,5 anhydro glucitol molecules placed in fbp aldolase. The mannitol isomer may be a better inhibitor of fbp aldolase compared to the glucitol derivative. But both molecules, however, may be 
effective inhibitors of this enzyme, since both unsubstituted 2,5 anhydro alditols are both inhibitors of fbp aldolase.

A mechanism for $\mathrm{H}^{-}$attack of an anomeric center of neokestose-1, 6-di-(hydrido) di-phosphate di-hydrate is shown in Figure 11.

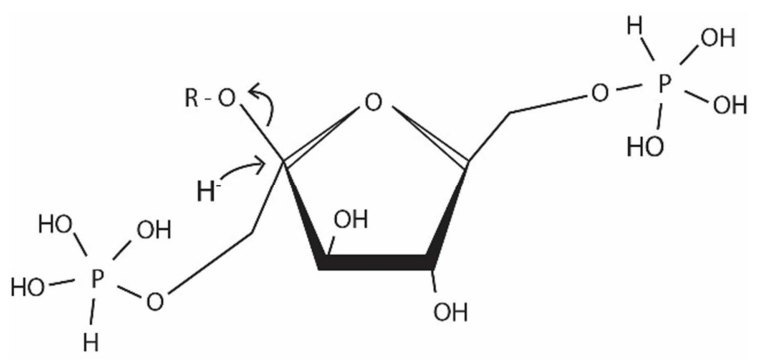

Figure 11. Proposed mechanism for the $\mathrm{H}$ attack of neokestose in $\mathrm{NH}_{4} \mathrm{OH}$ (1N, $p H 11.4)$.

Anomeric oxygen, $\mathrm{O}-2$, and $\mathrm{C}-1$ are in the same plane. O-5 and carbons $\mathrm{C}-2, \mathrm{C}-3$ and $\mathrm{C}-4$ are in a plane $107^{\circ}$ away, presumed to be tetrahedral, with respect to anomeric O-2. The available, unfilled, anti-bonding orbitals, $\sigma^{*}$, from the $\mathrm{C}$ 2-O-5 $\sigma$ bond and the C-2-C-3 $\sigma$ bond, as well as ring strain of the furanosyl ring, make nucleophilic attack, under an extended reaction time, 18 hours, at $\mathrm{C}-2$ by H$^{-}$, possible.

Workers have discovered a method to analyze linkage positions for carbohydrates to include furctofuranosides via reductive cleavage. [12-13]. Their conditions require anhydrous conditions and silylation and treatment with a strong base. Here the 2,5 anhydro mannitol (glucitol) molecules in aqueous conditions under conditions that do not remove the phosphate derivatives, (hydrido) phosphate hydrates, are made.

\section{Conclusions}

Neokestose-1,6-bisphosphate, found in ripe banana fruit, can be converted, with, to date unknown chemistry, to mannitol (glucitol)-1,6-di-(hydrido) di-phosphate di-hydrate. The reaction conditions are; $\mathrm{NaBH}_{4}$ in $\mathrm{NH}_{4} \mathrm{OH}(\mathrm{pH} 11.4,1 \mathrm{~N})$ for 18 hours. This mannitol or glucitol di-phosphate analogue may be a better inhibitor than 2,5 anhydro mannitol or 2,5 anhydro glucitol, which are known inhibitors of fructose 1,6 bisphosphate aldolase, because of the phosphate derivatives at the 1 and 6 positions of either the mannitol or the glucitol derivative. Preparation of these potential inhibitors could yield inexpensive treatments for destitute or low income cancer patients.

\section{References}

[1] Liberti, M.; Locasale, J.; The Warburg effect: how does it benefit cancer cells? Trends in Biochemical Sciences 41 (3) 211-218 (2016).

[2] Gray, G.; Barker, R.; Studies on the substrate of D-fructose 1,6 diphosphate aldolase in solution Biochemistry 9 (12) 24582462 (1970).

[3] Heinrich, J.; Koenig, W.; Bretting, H.; Separations of permethylated monosaccharides and 1,5 anhydro alditols and simultaneous determination of linkage positions and absolute configuration in the galactan of Helix pomatia. Carbohydr. Res. 299 (1-2) 1-6 (1997).

[4] Hartman, F.; Barker, R.; An exploration of the active site of aldolase using structural analogues of fructose diphosphate Biochemistry 4 (6) 1068-1075 (1965).

[5] Madson, M.; Method of isolating and identifying fruit oligosaccharides from ripe banana fruit US 9557335 B2 (2017).

[6] Madson, M; Mass Spectrometry Techniques for the structural characterization of glycans, Elsevier, New York, Amsterdam (2016).

[7] Christus, J.; Madson, M.; Structural characterization of a compound from the ethanol extract of banana fruit poster Spring ACS National Meeting, Denver CO (2015).

[8] Deslongchamps, P.; Stereoelectronic control in the cleavage of tetrahedral intermediates in the hydrolysis of esters and amides Tetrahedron 31 (20) 2463-2490 (1975).

[9] Deslongchamps, P.; Rowan, D.; Pothier, N.; G.; Saunders, J.; 1, 7-Dioxaspiro [5.5] undecanes. An excellent system for the study of stereoelectronic effects (anomeric and exo-anomeric effects) in acetals Canadian Journal of Chemistry 59 (7) 11051121 (1981).

[10] Christus, J.; Madson, M.; Possible treatment of Mycobacterium Lepromatous with bovine milk World Journal of Food Science and Technology 2 (3) 55-61 (2018).

[11] Christus, J.; Madson, M.; Possible Mimics of Duffy Binding Protein-II for Plasmodium vivax Binding Endothelial Cells or Binding Plasmodium falciparum by Mimicking Epitope on Erythrocyte Binding Antigen-175 A World Journal of Food Science and Technology 2 (2) 44-54 (2018).

[12] Rolf, D.; Gray, G.; Reductive cleavage of glycosides J. Am. Chem. Soc. 104 (12) 3539-354 (1982).

[13] Rolf, D.; Gray, G.; Analysis of the linkage positions in Dfructofuranosyl residues by the reductive-cleavage method Carbohydr. Res. 131 (1) 17-28 (1984). 